necessaries of life. It is satisfactory to know that the representations of the Italian doctor in the Honolulu newspaper procured for these outcasts some amelioration of their lot, although it procured for himself abuse and illwill. As a frontispiece to the volume there is a woodcut, reproduced from a photograph, of the author surrounded by some of the lepers of Molokai. Other woodcuts are likewise given; but they are chiefly, if not solely, remarkable for their very primitive and inartistic character.

Chemical Lessons.-Lecons de Chimie. Deuxième edition. Par M. Alfred Riche. (Paris: Didot Frères, I869.) LIKE almost all French treatises on elementary science, M. Riche's book is clearly and concisely written, and the illustrations are perfect; but although introducing many of the newest discoveries in the science (perhaps somewhat too pointedly alluded to in the preface), M. Riche does not adopt the important new views lying at the basis of modern chemistry. He still adheres to the old equivalent notation, and therefore refuses to admit the cogency of the proofs which have carried conviction to the minds of almost all other chemists. The short historical introductions under Combustion, the Atmosphere, Dissociation, and the Atomic Theory are of interest to the student, especially an extract (p. 704) from a paper by Dumas on the history of chemical affinity since the time of Barckhausen, read before the Academy of Sciences last year.

H. E, R.

\section{NOTES ON STALACTITES}

THE mineralogist is acquainted with few objects of greater beauty than the stalactitic forms assumed by many minerals. So curious are these natural growths, that I venture to offer a few remarks upon their artificial production.

The dependent clusters which line limestone caverns are formed, as has often been explained, by the following process:- When water containing carbonate of lime oozes through a porous rock, each drop loses water and carbonic acid by evaporation. As water saturated with carbonic acid only retains $0^{\circ} \mathrm{I}$ per cent. of carbonate of lime in solution, it follows that when the evaporation is continued beyond the point of saturation, carbonate of lime will be deposited. Globules of water on the roofs of limestone caverns are always covered with a thin film: this gradually thickens, and a tube is formed. This tube increases in size mainly by the deposition of carbonate of lime from water running over its surface. There are, however, many cavities containing tubes of arragonite in an horizontal position, and even of a curved form. $\mathrm{Mr}$. Wallace has shown $*$ that the growth of such stalactites has been from within outwards, the solution travelling along the self-constructed tube.

The following experiment affords a ready method of studying the somewhat rapid growth of similar forms:Select a flat piece of porous sandstone, or, better, a slice of coke; saturate this with nitric acid. If a globule of mercury three or four millimetres in diameter be allowed to fall on the coke, the surface of the mass will be covered with minute beads of mercury. The nitric acid immediately attacks the under-surface of each sphere, producing an annular ring of nitrate of mercury. A short tube is thus formed, sustaining the metallic globule. As liquids rise in capillary tubes, but do not overflow the orifice, the periphery of the sphere is acted upon by the nitric acid, and lifted higher and higher by the deposited nitrate. The result is a tube of about twenty-five millimetres (one inch) in height, terminated by a minute sphere of mercury.

The cross-section of the stalactite is tubular; often, however, partially filled with interlacing crystalline planes. If nitrate of mercury is deposited more rapidly on one side, a twist is given, and a spiral tube is formed. Often a thin wall on one side predisposes the direction, and a curved stalactite is produced.

It is well to consider briefly the stalactites that appear to have been formed mainly by deposition from water running over their surface. Of this class the siliceous stalactites well repay examination. Silica occurs in stalactite tubes of crystalline silicic anhydride, as in the specimens from Malwa, in Central India.

The chalcedonic form, however, is far more common, and the specimens from Trevascus Mine afford beautiful examples. The tubes are generally about two to three millimetres in diameter, and if a section through the length of the tube be made, the following structure will be easily made out by a hand lens or one inch objective. Firstly, we observe a slender opaque thread with a tube running down its entire length; over this opaque thread there is a covering of chalcedony. Frequently, but not invariably, the junction is marked by a vesicular structure.

To understand this it is necessary to turn to the artificial production of an aqueous solution of silica. By

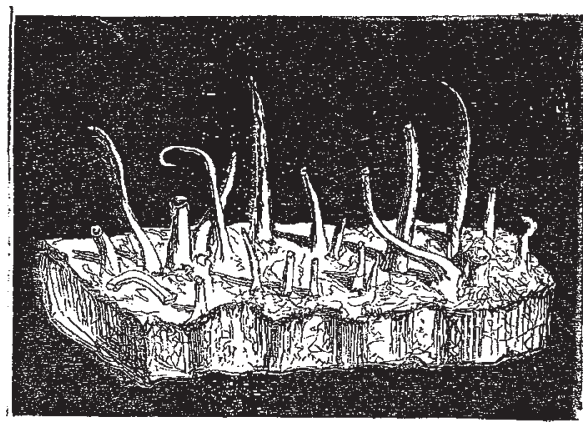

NITRATE OF MIERCURY STALACTITES

bringing together II 2 grammes of silicate of soda, $67^{\circ} 2$ grammes of dry hydrochloric acid, and I litre of water, and dialysing for four days, a solution containing $4^{\circ} 9$ per cent. of silicic anhydride remains upon the dialyser; the chloride of sodium and excess of hydrochloric acid having diffused away. This solution becomes pectous somewhat rapidly, forming a solid jelly which dries in air into a glassy, lustrous hydrate. A solution containing 0.5 per cent. of silicic anhydride remains permanently limpid.

The minutest trace of a soluble carbonate, or a bubble of carbonic acid, causes a solution of silica to gelatinise rapidly. Professor Church has shown the importance of this fact in the formation of siliceous pseudomorphs of corals. By passing water containing 0 I 5 per cent. of silica, dissolved carbonic acid, and air, over the coral, he replaced the carbonate of lime by hydrated silica.

In the Trevascus stalactite under consideration, probably the opaque thread was originally carbonate of lime. The carbonate would have arrested and gelatinised the silica, the covering thus produced affording a colloid septum for the diffusing away of crystalloid salts.

This view is supported by the vesicular junction with the chalcedonic layer, as the escape of carbonic acid would probably have produced bubbles in the yielding jelly. Whether this be so or not, it is easy to convert stalactites of arragonite into siliceous pseudomorphs that present a close resemblance to the natural mineral.

\section{W. ChandleR Roberts}

\section{THE SHARPEY PHYSIOLOGICAL} SCHOLARSHIP

$\mathrm{W}$

$\mathrm{E}$ are most pleased to report that the movement for the establishment of a "Sharpey Physiological Scholarship" at University College, in honour of Prof. Sharpey, is ineeting with all the success that it deserves. Already, by the more or less private efforts of the 
secretaries and other members of the committee, a sum of $\delta \mathrm{I}, 500$ has been subscribed: much more, however, will be required in order to carry out the wishes of the promoters of the "Sharpey Memorial" scheme.

Having held his present professorship since 1836 , Dr. Sharpey is well known to, and as thoroughly esteemed by, a very large number of old students, who have not only experienced the benefit of his clear, logical, and thorough method of teaching, but have felt the genial influence of his kindly sympathy, and the value of that breadth and soundness of judgment for which he is so remarkable. The large majority of his old and present students will now doubtless be delighted to take part in a movement destined to do honour to their favourite professor; and we believe that many of those who have been associated with Dr. Sharpey in his various official capacities in connection with science and education will also gladly avail themselves of this opportunity of testifying to their high appreciation of the valuable services which he has performed in both these capacities, and also of bearing witness to the strong feelings of personal regard with which he has inspired them.

The proposed memorial is of a nature likely to be peculiarly gratifying to Dr. Sharpey. The future "Sharpey Physiological Scholar" is destined to work in the Physiological Laboratory of the College, in the practical departments of the science; and successive students who may obtain this honourable distinction will, it is hoped, come for some time under the immediate stpervision of Dr. Sharpey himself. The Professor has most liberally offered to present to the College his anatomical and physiological library, consisting of the best works of the older anatomists, a useful series of foreign scientific periodicals, and a large number of monographs by some of the most active and learned observers of modern times. It is proposed to place these books in a new class-room for practical physiology, which is about to be fitted up under the name of the "Sharpey Physiological Laboratory and Library;" and which, as part of the memorial, is to be adorned by a portrait of the man to whom the subscribers wish to do honour now, and whose memory they desire to perpetuate in the future. If the amount of the "Memorial Fund" is sufficient, it is also proposed that a bust of Dr. Sharpey should be executed for presentation to the College. The plan seems an excellent one, combining as it does the feature of being a thorough personal tribute of the most gratifying nature to Dr. Sharpey, destined to convey to successive generations of students a notion of the high estimation in which his services in the cause of science and education were regarded by his contemporaries, whilst it is also a movement likely to result in the further extension of that branch of science to which he has himself principally contributed. It is hoped that the study of practical physiology will thus be helped on more than it has hitherto been in this country, and that in time a school of practical physiology - the precursor of many others-may be established, equal to any of the now celebrated continental schools. It is expected that many of the fellows of the Royal Society and of other scientific bodies will gladly take this opportunity of doing honour to a man whom they all esteem so highly, and for whom so many entertain warm feelings of personal regard. We are glad to find that several of the foremost amongst them have already given evidences of substantial co-operation, and we trust that many others will follow their example.

\section{THE ISTHMIAN WAY TO INDIA}

THE Canal has been opened. The flotilla, with its noble, royal, imperial, and scientific freight, has progressed along the new-made way from sea to sea. From Port Saï, that new town between the sea and the wilderness, with its ten thousand inhabitants, and acres of workshops and building-yards, and busy steam-engines, the naval train floated through sandy wastes, across lakes of sludge and lakes of water filled from the Salt Sea; past levels where a few palm-trees adorn the scorched landscape; past hill-slopes on which the tamarisk waves its thready arms ; past swamps where flocks of flamingoes, pelicans, and spoonbills, disturbed by the unwonted spectacle, sent up discordant cries; through deep excavations of hard sand or rock; across the low flat of the Suez lagoons, where Biblical topographers have searched for the track of the children of Israel ; and so to the "red" waters of the great Gulf of Arabia. The flotilla has done its work: the Canal has been opened; and the distance by water to India is now 8,000 miles, instead of the 15,000 miles by the old route round the Cape of Good Hope.

It is a great achievement. So great, that we need not wonder that the capital of $8,000,000 l$. sterling with which it was commenced in I 859 was all expended, and as much more required, before the work was half accomplished. And perhaps we ought not to be too much overcome with pity for the 20,000 unlucky Egyptians-natives of the house of bondage-pressed every month up to the year I 863 by their paternal Government to labour, wherever required, along the line of excavations. How persistent are Oriental customs! Here we have in modern daysthe days of power-looms, of steam printing-presses, and under-sea telegraphs-a touch of the old tyranny, the taskmasters and the groanings, associated in our memories with the very earliest of Egyptian history.

The length of the Canal is one hundred miles, and the depth, as the French engineers inform us, is to be everywhere twenty-eight feet, so as to admit of the passage of large vessels. It must not be supposed that an excavation of the depth above mentioned has been dug all across the Isthmus, for the level of the country is, for the most part, below that of the Mediterranean; consequently, miles of banks have been thrown up across the lowest tracts to form a channel for the water. In looking at a section of the whole route from Saïd to Suez-seventy-five miles in a direct line from sea to sea-the great extent of depression is well seen. In Lake Timsah it is about eighteen feet; in the Bitter Lakes, which stretch to a length of twenty-five miles, it is in places twenty-six feet. On the other hand, the elevations, though comparatively few, are somewhat formidable of aspect, particularly at Ei Guier and at Chalouf. The more this section is studied, the more forcible becomes the impression on the mind that a strait thickly studded with islands, as Behring's Strait, once separated Asia and Africa, and that by the drift from the Nile and the desert the sea has been filled up around the islands, with the exception of the lake depressions, until the present Isthmus was formed. Hence the difference of soil. The islands rising boldly up : El Guier, ten miles long, layers of sand and hard clay; Serapeum, three miles long, a kind of shelly limestone; and Chalouf, six miles long, composed of hard clay, sandstone rock, and conglomerate, the severest part of the excavation. Geologists have remarked upon the fact that the fossils found in the Chalouf ridge are identical with those of the London basin and the hill of Montmartre, whereby we learn that parts of Egypt, France, and England are of the same age.

The mountains of Abyssinia are every year diminished in size and height by the enormous periodical rains which wash down millions of cubic feet of mud and clay into the Nile. Vast clouds of sand are blown into the great river in its long course through the deserts; and these transported matters, caught by the strong current setting in from the Straits of Gibraltar, have been drifted to the eastward during immemorial ages, with consequences which are well known to those who have studied the geography and geology of the Isthmus. Such a trans. formation will be recognised as one of the ordinary operations of nature, when we remember that in 4,150 years the valley of the Nile has been raised eleven feet by 